\title{
Accounting
}

\section{Nonlinearity between financial development and the shadow economy: Evidence from Jordan}

\author{
Ziad M. Abu-Lila ${ }^{a^{*}}$, Sameh Ajlouni ${ }^{\mathrm{b}}$ and Abdallah Ghazo ${ }^{a}$
}

${ }^{a}$ Assistant Professor, Department of Economics of Finance and Business, Faculty of Economics and Administrative Sciences, Al-Albayt University, Jordan ${ }^{b}$ Assistant Professor, Department of Economics, Faculty of Economics and Administrative Sciences, Yarmouk University, Jordan

\section{H R O N I C L E}

Article history:

Received: November 15, 2020

Received in revised format:

January 282021

Accepted: March 2, 2021

Available online:

March 2, 2021

Keywords:

The shadow economy

Financial development

Cointegration

Jordan

\section{A B S T R A C T}

The present study empirically investigates the long-run nonlinear relationship between the shadow economy and financial development targeting developing small open countries, such as Jordan. The study applied the cointegration test as an estimation technique in order to achieve its aim. The data used were mainly taken from Jordanian economy during the period (1990-2019). According to the test of Johanson cointegration, the empirical results of this study showed evidence of a long run inverted U-shaped relationship between the shadow economy and financial development. The results also showed that there is a long run positive relationship between inflation and the shadow economy. Consequently, these results lead to a profound implication when adopting policies to reduce the size of the shadow economy.

\section{Introduction}

The shadow economy, also known as the hidden or informal economy, describes the unauthorized economic activities of the official agents. According to Smith (1994) the shadow economy includes the production of goods and services, whether from legal or illegal activities, that are not recorded in the official records of gross domestic product. While Manolas et al. (2013) indicated that the shadow economy consists of all outputs that are not reported, and are hidden from income taxes. Whether these outputs are from legal activities such as transactions between companies and retailers, that are paid without being officially registered to avoid paying taxes, or from illegal activities like the drug trade. Therefore, the shadow economy consists of all activities that cannot be measured due to the lack of any official statistics related to them even though they contribute to adding value (Schneider, 1986). The shadow economy phenomenon arises for many reasons. One of these reasons is the high and unjust tax burden. Another reason is the contribution to social security as well as the multitude of regulatory procedures. In addition, the attempts of individuals or firms to moderate the impact of low income in the formal economy during the recession periods, through the activities of the informal economy. All these factors contribute to increasing the size of this phenomenon (Schneider et al., 2010). Furthermore, the needs to meet legal labor market standards; such as minimum wages, the maximum number of working hours, public safety standards, etc., which may urge firms to be involved in the activities of the informal economy. Illegal activities such as theft, drug trade and household activities also increase the size of the shadow economy (Schneider \& Williams, 2013).

\footnotetext{
* Corresponding author

E-mail address: abu-lila@aabu.edu.jo (Z.M. Abu-Lila) 
The determinants of the shadow economy and their expected effects on the size of the shadow economy differ from one country to another. Therefore, there is a difference in the size of the shadow economy across countries. According to the working paper published by an International Monetary Fund and applied to 158 countries during the period (1991-2015), it was found that the average ratio of the shadow economy to GDP was 31.9\% in these countries. Precisely, the highest percentages were in Zimbabwe and Bolivia, with $60.6 \%$ and $62.3 \%$, respectively, whereas the lowest percentages were in Austria with $8.9 \%$ and in Switzerland with 7.2\% (Medina \& Schneider, 2018). Although there are no official statistics on this phenomenon, previous studies used many methods to estimate the size of the shadow economy. According to Dell'Anno et al. (2007), the approaches that were applied to estimate the shadow economy could be classified into direct and indirect approaches. The direct approach depends on contacts with individuals or firms to collect direct information concerning undeclared income. On the other hand, the indirect approach determines the size of the hidden economy by measuring the effects of the shadow economy on the official statistics, and it mainly uses macroeconomic data. Such approaches can be divided into six categories: (1) the discrepancy between the national expenditure and income statistics; (2) the discrepancy between the official and the real labor force statistics; (3) the transaction approach; (4) MIMIC approach; (5) the physical input approach; and (6) the cash deposit ratio approach which is used in this study. The phenomenon of the shadow economy is of interest to many studies since it has many impacts on individuals and societies. As the shadow economy reduces the tax base, it also reduces tax revenues. However, the activities of the shadow economy are not included in the national income accounts. This gives wrong indicators to policy makers. Furthermore, the shadow economy leads to distortions in the allocation of resources, especially in the labor market. Institutions that operate in the shadow economy are not subject to labor regulations, and employment in this sector is not subject to healthy and safe working conditions. Moreover, they work at low wages (Habibullah et al., 2016).

Nevertheless, this phenomenon could present some positive effects, such as job opportunities, especially during the periods of crisis. It could also provide some goods and services at a lower price level as a result of lower costs. Moreover, it enables dynamism to the economy and leads to the accumulation and growth of capital. However, the negative effects of this phenomenon exceed the positive effects, since it leads to a decrease in the value of GNP. It also leads to tax injustice, an insufficient account of the size of the public sector, a budget deficit due to insufficient taxes, excessive unemployment and inflation rates, an unfair distribution of income, inaccurate calculations of indicators of exports and imports, loss of welfare and corruption in Society and other negative effects (Erdinc, 2016). In the view of the multiplicity of the expected negative effects of the shadow economy, countries have attempted to fight this phenomenon through using various policies and procedures. Moreover, they have worked to strengthen the determinants whose role is reducing the size of the shadow economy. Financial development is considered as one of the main determinates that can reduce the size of the shadow economy through the role of the financial development in providing financial services at a lower cost. This leads to increasing the opportunity cost of working in the shadow economy activities.

Studies in Jordan, have rarely targeted the determinants of the shadow economy in spite of its importance in determining the variables that can limit the spread of the shadow economy phenomenon. On the other hand, most studies focused on measuring the size of the shadow economy and its impacts on the Jordanian economic variables. This is what gives this study great significance, given that it seeks to provide empirical evidence on the importance of financial development in reducing this phenomenon, using annual data on the Jordanian economy during the period (1990-2019).

The study problem emerges as a result of the efforts expended by governments in searching about the factors that can reduce the size of the shadow economy. Moreover, the various policies it follows, the size of the shadow economy is still high. Finally, the rest of this study is organized as follows: The first section presented an introduction to the subject, while the Second section presents the theoretical framework and literature review, the third section sets out the methodology, and the fourth section deals with the empirical results. Eventually, the study presents its conclusion and policy implications.

\section{Theoretical Framework and Literature Review}

The studies explain the phenomenon of the shadow economy and use several variables in order to determine the factors that encourage individuals and firms to participate in the shadow economy activities. In the scope of this study, are concerned with the studies that focused on the role of financial development in reducing the size of the shadow economy. Capasso and Jappelli (2013) indicated that increasing financial development leads to an increase in the opportunity cost of working in the shadow economy activities, which reduces the demand for these activities and gives an incentive for agents to work in formal sectors. In addition, financial development provides the government with an effective tool which monitors economic transactions and, thus, reduces the incidence of tax evasion (Blackburn, et al. 2012). Moreover, the impact of financial development on the shadow economy varies between countries, as Canh and Thanh (2020) noted that the impact of financial development on the shadow economy might be stronger in lower income countries. In order to measure the impact of financial development on the shadow economy, there are many methodologies, econometric methods and models that have been built to achieve this goal. Some of these studies used panel data to examine the effect of financial development on the size of the shadow economy across countries 
like the study of Bayar and Ozturk (2016), Berdiev and Saunoris (2016), and Canh and Thanh (2020). In these studies, the shadow economy is estimated as a function of financial development and other control variables:

$$
S E=f(F D, \text { Control })
$$

where: SE denotes the shadow economy, FD is the level of financial development and Control represents to control variables which includes institutional quality, the level of development, political stability, corruption, tax burden or other variables related to the shadow economy. Some studies focused on the effect of financial development on the size of the shadow economy, in the scope of a specified country, such as the study of Beck and Hoseini (2014), and the study of Katircioglu and Imamoglu (2020). On the other hand, other studies used a non-linear model to determine the relationship between the shadow economy and its determinants such as the study of Habibullah, et al. (2016) and Canh and Thanh (2020). In these studies, the models were built to estimate the shadow economy as a function of financial development, square term of financial development and other control variables. The model can be as follows:

$$
S E=f\left(F D, F D^{2}, \text { Control }\right)
$$

The main findings of these and other studies are concerned with the importance of financial development in explaining the phenomenon of the shadow economy. For example, the study of Bose, et al. (2012) used data for 119 countries for the period $1999 / 2000$ to 2004/2005 to investigate the impact of banking development on the size of shadow economies. The results indicated that the development of the banking sector is associated with a smaller shadow economy in a wide cross-section of countries. Moreover, the depth and efficiency of the banking sector equally matter in reducing the size of the shadow economy. According to Capasso and Jappelli (2013), it was found that the financial development reduces both tax evasion and the size of the shadow economy. They reached this conclusion through using Italian microeconomic data to construct a micro-based index of the shadow economy. The main finding of their study indicated that the local financial development is associated with a smaller size of the shadow economy. Within the same context, Berdiev and Saunoris (2016) aimed to examine the dynamic relationship between financial development and the shadow economy based on data for 116 countries during the period (19602009). The main results of the VAR model and the impulse response function which were applied stated that the shock of financial development negatively affects the shadow economy, and the shock of the shadow economy impedes financial development. Bayar and FarukOzturk (2016) also focused on the interaction between the shadow economy, financial development and institutional quality in their study on the transition economies of the European Union during the period (20032014). The study concluded with a set of results that showed a cointegration relationship between the shadow economy, financial development and institutional quality. Furthermore, it was found that financial development and institutional quality have a negative impact on the shadow economy in the long run.

The study of Henri (2018) investigated the relationship between the size of the shadow economy and financial development using data for 41 Sub-Saharan African countries during the period (1991-2015). It used Ordinary Least Squared, Fixed effects and Generalized Method of Moment. Henri (2018) found that the financial development is measured by the broad money and domestic credit for the private sector has a negative and statistically significant impact on the shadow economy. This clearly suggests that financial development reduces the size of the shadow economy.

\section{Methodology}

\subsection{Data}

The data of the shadow economy is defined as a ratio of GDP. There are many approaches to measure the size of the shadow economy. In this study the size of the shadow economy was computed by using the modified cash deposit ratio approach proposed by Pickhardt and Sarda (2011, 2013). The same approach was also used by Habibullah et al. (2016) and other scholars in the field. It depends on the following formula:

$$
\frac{C_{t}-C_{0}}{C_{0}+D_{t}}=\frac{Y_{U t}}{Y_{L t}}
$$

where: $C_{t}$ is currency in circulation in period $t, C_{0}$ is currency in circulation in the base year (here 1990), and $\mathrm{D}_{t}$ denotes demand deposits in year $t, \mathrm{Y}_{\mathrm{Ut}}$ and $\mathrm{Y}_{\mathrm{Lt}}$ represent the size of the shadow economy and the legal economy respectively. Therefore, $Y_{U t} / Y_{L t}$ measures the ratio of the shadow economy to the legal economy in period t. It is represented by $\mathrm{SE}_{\mathrm{t}}$ in this paper. 
Furthermore, this study used the ratio of domestic credit to the private sector to GDP as a proxy measure for financial development $\left(\mathrm{FD}_{\mathrm{t}}\right)$ as measured by many researchers, such as Lynch (1996), Calderon and Liu (2003) and others. Moreover, the inflation rate $\left(\mathrm{Inf}_{\mathrm{t}}\right)$ was measured by the percentage change in GDP deflator. Finally, the data were collected from several sources such as the central bank of Jordan and the World Bank.

\subsection{Model Specification}

In order to identify the determinants of the shadow economy, many models were built for this purpose, and several variables were employed to explain this phenomenon. In the current study, the model was built by estimating the ratio of the shadow economy to the GDP as a function of inflation and financial development. Therefore, the model for this study can be specified as follows:

$$
\mathrm{SE}=\mathrm{f}(\mathrm{FD}, \text { Inf }) .
$$

Since the aim of this study is to estimate the non-linear relationship between the shadow economy and financial development, the function No. (1) was estimated in an exponential form, as the following:

$$
S E_{t}=\beta_{0}+\beta_{1} \operatorname{Inf}_{t}+\beta_{2} F D_{t}+\beta_{3} F D_{t}^{2}+\varepsilon_{t}
$$

where:

$\mathrm{SE}_{\mathrm{t}}$ : is the ratio of the shadow economy to GDP in period t.

Inf $_{\mathrm{t}}$ : is the inflation rate in period $\mathrm{t}$.

$\mathrm{FD}_{\mathrm{t}}$ : is financial development in period $\mathrm{t}$.

$\mathrm{FD}_{\mathrm{t}}{ }^{2}$ : is the square term of financial development in period $\mathrm{t}$.

$\beta_{0}, \beta_{1}, \beta_{2}$ and $\beta_{3}$ : are parameters for estimating.

$\varepsilon_{t}:$ errors term.

This study can contribute to the existing literature by using inflation as a determinant for the shadow economy because of the scarcity of studies that used this variable to explain the phenomenon of the shadow economy. In contrast, most studies concentrated on explaining the effects of the shadow economy on inflation. The justification for using inflation in the shadow economy function depends on the expected positive effect of inflation on the shadow economy since the increase in the inflation rate will reduce the purchasing power of money. This motivates individuals to expand their activities in the shadow economy in order to maintain a certain level of the standard of living.

\section{Empirical Results}

Estimating Eq. (2) could persist spurious regression since it depends on time series. Spurious regression arises if a nonstationary time series is regressed on another nonstationary time series (Gujarati, 2003). Therefore, to avoid the problem of spurious regression, the first step in estimating this equation implied testing the stationary of time series. Moreover, based on the results of the unit root test determined the appropriate methods to estimate Eq. (2) were determined. Existing literature have presented many methods for testing a unit root test, in this study the Augmented Dicky Fuller test (ADF) was employed. In the ADF test, the null hypothesis stated that when there is unit root, the time series is nonstationary. On the other hand, the alternative hypothesis is that the time series is stationary (Gujarati, 2003). If the null hypothesis is rejected, it means that the variable is stationary. Moreover, this test can be applied to data at level, first difference or at second difference. In Table 1, the study presented the results of the unit root test for the variables that used in Eq. (2). The results of this test clearly indicate that all variables are non stationary at level. Therefore, the test was repeated at the first difference, and it was found that the data were stationary at the first difference.

Table 1

\begin{tabular}{|c|c|c|c|c|c|c|}
\hline \multirow[t]{2}{*}{ Variables } & \multicolumn{3}{|l|}{ Level } & \multicolumn{3}{|c|}{ First Difference } \\
\hline & ADF Statistic & Critical Value at $5 \%$ & Lags & ADF Statistic & Critical Value at $5 \%$ & Lags \\
\hline $\mathrm{SE}$ & -0.29 & -2.98 & 1 & $-3.1 *$ & -1.95 & 1 \\
\hline FD & -2.30 & -2.99 & 4 & $-2.03 *$ & -1.96 & 3 \\
\hline Inf & -1.99 & -2.98 & 1 & $-4.97 *$ & -1.95 & 1 \\
\hline
\end{tabular}

ADF results

* Denotes the null hypothesis is rejected at $5 \%$ level

- an optimal lag length determined through the minimum value of Akaike's information criterion AIC. 
The results of the ADF suggest that the study can apply the cointegration test to determine the long run relationship between variables as specified in Eq. (2). Therefore, the Johanson cointegration methods were applied to determine if there is a cointegration relationship between variables.

Table 2

The results of Johanson cointegration test

\begin{tabular}{|c|c|c|c|c|c|}
\hline $\begin{array}{l}\text { Hypothesized } \\
\text { No. of CE (S) }\end{array}$ & Eigen value & Trace statistics & Critical Value at $5 \%$ & $\begin{array}{l}\text { Max-Eigen } \\
\text { statistics }\end{array}$ & $\begin{array}{l}\text { Critical Value at } \\
5 \%\end{array}$ \\
\hline None & 0.934 & $121.71^{*}$ & 63.88 & $67.93^{*}$ & 32.12 \\
\hline At most 1 & 0.617 & $53.78^{*}$ & 42.92 & 24.01 & 25.82 \\
\hline At most 2 & 0.507 & $29.76^{*}$ & 25.87 & 17.69 & 19.39 \\
\hline At most 3 & 0.383 & 12.07 & 12.52 & 12.07 & 12.52 \\
\hline
\end{tabular}

* Denotes the null hypothesis is rejected at $5 \%$ level

In Table 2, the results of the trace and max-eigen test for cointegration were presented. They suggested the existence of a long run relationship between variables at 5\% level. In addition to this, the cointegration equation could be rewritten after adjusting the sign of independent variables as follows:

$$
\begin{array}{r}
S E_{t}=525.04+1.55 \operatorname{Inf}_{t}+13.7 F D_{t}-0.09 F D_{t}^{2}+1.79 \text { trend } \\
(0.26)^{*}(1.78)^{*}(0.01)^{*} \quad(0.06)^{*}
\end{array}
$$

Note: the value in parentheses is standard error and * denotes variable is significance at $5 \%$ level.

According to the results of Eq. (3), there is a long run positive relationship between inflation and the shadow economy. This implies that the increase in inflation rate encourages individuals and firms to raise their participation in the shadow economy activities in order to offset the decrease in the purchasing power. On the other hand, the signs of financial development coefficient and its square term were positive and negative respectively. Thus, it is assumed that the relationship between the shadow economy and financial development takes an inverted U-shape in the long run. This means that at a lower level of financial development, the access to finance is difficult and costly, and individuals seek in the shadow economy to find an alternative way to finance their transactions. However, since the financial sector develops ways of financing to become easier and cheaper, the opportunity cost to participate in the shadow economy becomes greater.

\section{Conclusion and Policy Implications}

This paper attempts to provide an empirical investigation of the long-run nonlinear relationship between the shadow economy and financial development targeting developing small open economies, such as the economy of Jordan. In addition, the paper used one control variable, namely inflation rate. The cointegration test was carried out in order to achieve the aim of this study using data from Jordan during the period (1990-2019). The empirical results showed evidence of a long run inverted U-shaped relationship between the shadow economy and financial development. Therefore, it was and this result indicated that at a lower level of financial development, the access to finance is difficult and costly, and individuals seek in the shadow economy to find an alternative way for financing. However, as the financial sector develops the ways of financing to become easier and cheaper, the opportunity cost to participate in the shadow economy becomes greater. Moreover, the results also indicated that there is a long run positive relationship between inflation and the shadow economy. This implies that an increase in the inflation rate motivates individuals and firms to raise their participation in the shadow economy activities to offset the decrease in the purchasing power.

The findings of this paper have implications for policy makers based on the relationships established in this paper. For instance, when adopting policies that aim to reduce the size of the shadow economy, developing the financial system must be taken into consideration in order to increase the opportunity cost of operating in the shadow economy activities. Additionally, more attention should be devoted to stimulating financial institutions to employ advanced techniques and methods that facilitate the process of completing payments in order to reduce the activities of the shadow economy and reduce tax evasion. Policy makers must also adopt policies that work to maintain the stability of price levels and thus limit the rise in inflation rates because of their positive effects on the size of the shadow economy. 


\section{References}

Bayar, Y., \& FarukOzturk, O. (2016), Financial Development and Shadow Economy in European Union Transition Economies. Managing Global Transitions, 14(2), 157-173.

Beck, T., \& Hoseini, M. (2014). Informality and Access to Finance: Evidence from India. CentER Discussion Paper Series No. 2014-052.

Berdiev, A., \& Saunoris, J. (2016). Financial development and the shadow economy: A panel VAR analysis. Economic Modelling, 57, 197-207.

Blackburn, K., Bose, N., \& Capasso, S. (2012). Tax evasion, the underground economy and financial development, Journal of Economic Behavior and Organization, 83(2), 243-253.

Bose, N., Capasso, S., \& Andreas Wurm, M. (2012). The impact of banking development on the size of shadow economies. Journal of Economic Studies, 39(6), 620-638.

Calderon, C., \& Liu, L. (2003). The direction of causality between financial development and economic growth. Journal of Development Economics, 72(1), 321-334.

Canh. N., \& Thanh, S. (2020). Financial development and the shadow economy: A multi-dimensional analysis. Economic Analysis and Policy, 67, 37-54.

Capasso, S., \& Jappelli, T. (2013). Financial development and the underground economy. Journal of Development Economics, $101,167-178$.

Dell'Anno, R., Gómez-Antonio, M., \& Alañon-Pardo, A. (2007). The shadow economy in three Mediterranean countries: France, Spain and Greece. A MIMIC approach. Empirical Economics, 33, 51-84.

Erdinc, Z. (2016). The Reasons of Underground Economy, Its Results, Methods and the Turkish Case. Journal of Business and Economic Policy, 3(1), 15-21.

Gujarati, D. (2003). Basic Econometrics. Fourth Edition, The McGraw-Hill Companies.

Habibullah, M., Din, B.,Yusof-Saari, M., \& Baharom, A. (2016). Shadow Economy and Financial Sector Development in Malaysia. International Journal of Economics and Financial Issues, 6(S7), 181-185.

Henri, N. (2018). Does financial development reduce the size of the informal economy in Sub-Saharan African countries? MPRA Paper 89851, University Library of Munich, Germany.

Katircioglu, S., \& Imamoglu, H. (2020). Spillover effects of financial development on the informal economic activity Empirical evidence from Turkey. International Journal of Islamic and Middle Eastern Finance and Management, 13(3), $471-482$.

Lynch, D. (1996). Measuring financial sector development: A study of selected Asia-Pacific countries. The Developing Economies, 34, 3-33.

Manolas, G., Rontos, K., Sfakianakis, G., \& Vavouras, I. (2013), The Determinants of the Shadow Economy: The Case of Greece. International Journal of Criminology and Sociological Theory, 6(1), 1036-1047.

Medina, L., \& Schneider, F. (2018). Shadow Economies Around the World: What Did We Learn Over the Last 20 Years?IMF Working Paper, WP/18/17.

Pickhardt, C., \& Sarda, J. (2011). The size of the underground economy in Germany: A correction of the record and new evidence from the modified-cash-deposit-ratio approach. European Journal of Law and Economics, 32(1), 143-163.

Pickhardt, C., \& Sarda, J. (2013). Size and causes of the shadow economy inSpain: Acorrection of the record and new evidence from the MCDR approach. European Journal of Law and Economics, 39(2), 403-429.

Schneider, F. (1986). Estimating the size of the Danish shadow economy using the currency demand approach: an attempt. Scandinavian Journal of Economics, 88(4), 643-68.

Schneider, F., Buehn, A., \& Montenegro, C. (2010). New Estimates for the Shadow Economies All over the World. International Economic Journal, 24(4), 443-461.

Schneider, F., \& Williams, C.C. (2013). The Shadow Economy. The Institute of Economic Affairs, London.

Smith, P. (1994). Assessing the size of the underground economy: The Canadian statistical perspectives. Canadian Economic Observer, no. 11-010, 16-33.

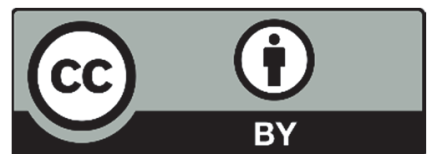

(C) 2021 by the authors; licensee Growing Science, Canada. This is an open access article distributed under the terms and conditions of the Creative Commons Attribution (CC-BY) license (http://creativecommons.org/licenses/by/4.0/). 